\begin{tabular}{|c|c|c|}
\hline UE & $\begin{array}{c}\text { GEOAMBIENTE ON-LINE } \\
\text { Revista Eletrônica do Curso de Geografia - UFG/REJ } \\
\text { Graduacãao e Pós-Graduacão em Geografia } \\
\text { http://revistas.ufg.br/index.php/geoambiente/index } \\
\text { Apoio: PRPG/PROAPUPEC } \\
\text { Jatai-GO | n 29| Jul-Dez/2017 }\end{array}$ & $\begin{array}{l}\text { OGEO } \\
\text { ISSN } 1679-9860 \\
\text { ISAMBIENTE }\end{array}$ \\
\hline
\end{tabular}

\title{
CARACTERIZAÇÃO MORFOMÉTRICA DA BACIA HIDROGRÁFICA DO RIO IVAÍ - PARANÁ
}

\author{
Camila Furlan de Souza, Carla Talita Pertille, Bruno Jan Schramm Corrêa, Francielle \\ Santos Vieira \\ (Universidade do Estado de Santa Catarina, Mestrando(a) em Engenharia Florestal, \\ camilafurlan.florestal@gmail.com; carla_pertille@hotmail.com; brschramm74@gmail.com; \\ francielle.florestal@outlook.com)
}

Resumo: O objetivo desse estudo foi avaliar as propriedades morfométricas da bacia do Rio Ivaí, utilizando técnicas de geoprocessamento de forma a fornecer dados para planejamento e gestão de bacias hidrográficas do Estado do Paraná. O processamento dos dados foi realizado em ambiente SIG utilizando o aplicativo computacional ArcGIS 10.4/ArcMap®. Os parâmetros morfométricos avaliados foram: coeficiente de compacidade, fator de forma, índice de circularidade, índice de rugosidade, índice de alongamento, razão de elongação, índice de sinuosidade, razão de relevo, densidade de drenagem, densidade hidrográfica e coeficiente de manutenção. Os resultados para fator de forma e índice de circularidade foram muito baixos, o que indica o formato mais alongado da bacia. Enquanto o coeficiente de compacidade apresentou um valor alto, o que caracteriza uma baixa propensão à ocorrência de enchentes em condições normais de precipitação. A bacia é classificada como de $5^{\text {a }}$ ordem, ou seja, bem ramificada. Além disso, o relevo é caracterizado principalmente pela classe suavemente ondulado (47,15\%), seguido da classe ondulado (29,99\%). Conclui-se que a análise dos dados morfométricos permitiu compreender o regime hidrológico e inferir sobre o manejo e conservação da bacia do rio Ivaí.

Palavras-chave: recursos hídricos; geoprocessamento; coeficiente de compacidade.

\section{MORPHOMETRIC CHARACTERIZATION OF THE HYDROGRAPHIC BASIN OF THE RIVER IVAÍ - PARANÁ}

Abstract: The objective of this study was to evaluate the morphometric properties of the Ivaí river basin using geoprocessing techniques in order to provide data for planning and 


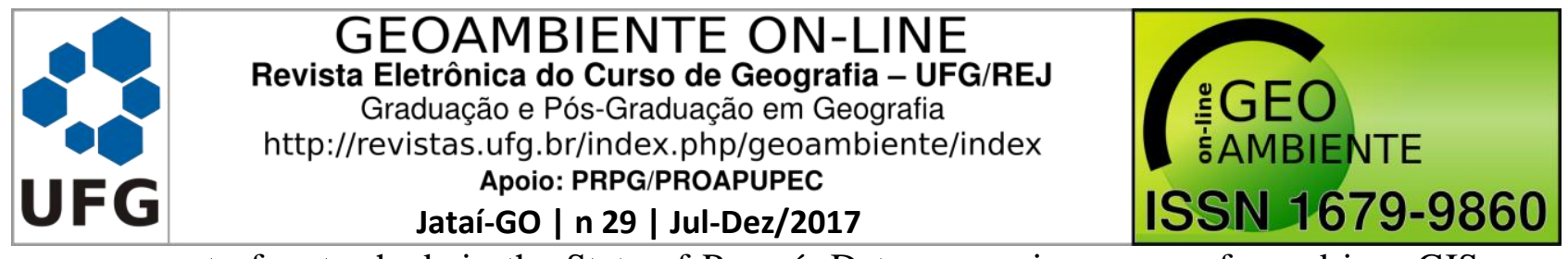

management of watersheds in the State of Paraná. Data processing was performed in a GIS environment using the ArcGIS 10.4 / ArcMap® computer application. The morphometric parameters evaluated were: compactness coefficient, shape factor, circularity index, roughness index, elongation index, elongation ratio, sinuosity index, relief ratio, drainage density, hydrographic density and maintenance coefficient. The results for form factor and circularity index were very low, indicating the more elongated shape of the basin. While the coefficient of compactness presented a high value, which characterizes a low propensity to the occurrence of floods in normal conditions of precipitation. The basin is classified as 5 th order, that is, well branched. In addition, the relief is characterized mainly by the gently waved class $(47.15 \%)$, followed by the wavy class $(29.99 \%)$. It was concluded that the analysis of the morphometric data allowed understanding the hydrological regime and inferring about the management and conservation of the Ivaí river basin.

Keywords: water resources; geoprocessing; compactness coefficient.

\section{CARACTERIZACIÓN MORFOMÉTRICA DE LA CUENCA DEL RIO IVAI - PARANÁ}

Resumen: El objetivo de este estudio fue evaluar las propiedades morfométricas de la cuenca del río Ivaí, utilizando técnicas de geoprocesamiento para proporcionar datos para la planificación y gestión de cuencas del Estado de Paraná. El procesamiento de los datos fue realizado en ambiente SIG utilizando la aplicación computacional ArcGIS 10.4 / ArcMap®. Los parámetros morfométricos evaluados fueron: coeficiente de compacidad, factor de forma, índice de circularidad, índice de rugosidad, índice de estiramiento, razón de elongación, índice de sinuosidad, razón de relieve, densidad de drenaje, densidad hidrográfica y coeficiente de mantenimiento. Los resultados para el factor de forma y el índice de circularidad fueron muy bajos, lo que indica el formato más alargado de la cuenca. Mientras que el coeficiente de compacidad presentó un valor alto, lo que caracteriza una baja propensión a la ocurrencia de inundaciones en condiciones normales de precipitación. La cuenca se clasifica como de quinto orden, es decir, bien ramificada. Además, el relieve se caracteriza principalmente por la clase suavemente ondulada $(47,15 \%)$, seguida de la clase ondulada $(29,99 \%)$. Se concluye que el análisis de los datos morfométricos permitió comprender el régimen hidrológico e inferir sobre el manejo y conservación de la cuenca del río Ivaí.

Palabras clave: recursos hídricos; geoprocesamiento; coeficiente de compacidad. 


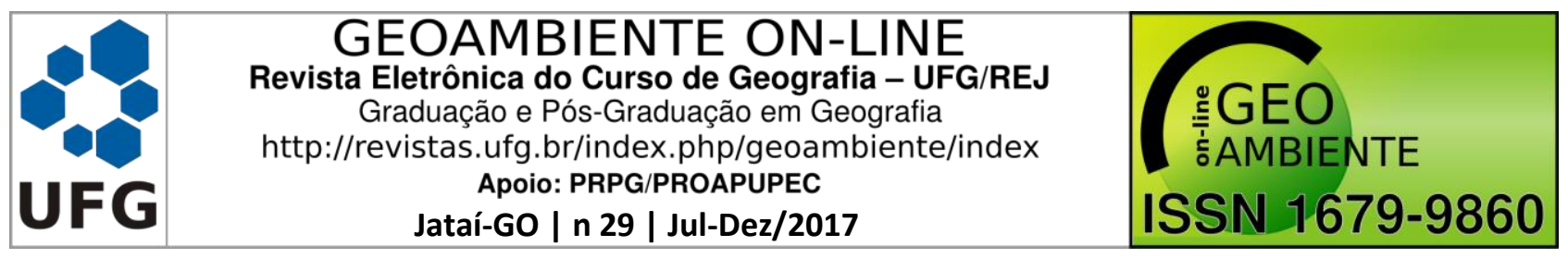

\section{Introdução}

As propriedades físicas e bióticas de uma bacia hidrográfica desempenham funções significativas no ciclo hidrológico e podem afetar a infiltração, a quantidade de água produzida como deflúvio, a evapotranspiração e o escoamento superficial (TONELLO et al., 2006).

Dessa forma, as bacias hidrográficas podem ser conceituadas como um complexo sistema biofísico que abrange a relação entre as atividades humanas e os recursos ambientais que demandam práticas sustentáveis de uso do solo (TRINDADE e RODRIGUES, 2016).

Nesse sentido, é importante caracterizar bacias hidrográficas utilizando a análise morfométrica, a qual expõe parâmetros morfológicos e seus processos, afim de identificar alterações com ou sem influências antropogênicas. Tais informações servem como subsídio para a análise de fenômenos geológicos, sujeitos a variações significativas para a compreensão das mudanças ambientais antrópicas (PISSARRA et al., 2010).

Atualmente, a caracterização morfométrica de bacias hidrográficas é feita com a integração de informações de relevo em ambiente de Sistema de Informações Geográficas (SIG) (CARDOSO et al., 2006). Esse processo envolve estudos relacionados ao relevo (ALVES et al., 2016), os quais são de suma importância na determinação das potencialidades e limitações quanto ao uso do solo, contribuindo para a programação das atividades (FRAGA et al., 2014).

De acordo com Xaud e Epiphanio (2015), o Sensoriamento Remoto e as técnicas que envolvem análise de dados, especialmente as de detecção de mudanças, apresentam alta potencialidade na quantificação e qualificação do uso da terra e cobertura vegetal, bem como de processos de conversão e modificação. Um produto do Sensoriamento Remoto que se destaca nesse processo, é a imagem SRTM (Shuttle Radar TopographyMission). A união dessa imagem com as ferramentas de geoprocessamento, possibilita a obtenção de parâmetros morfométricos descritos em equações propostas por Horton (1945), Strahler (1952), Schumm (1956), Melton (1957), Schumm (1963), Villela e Mattos (1975), para a análise morfométrica de uma bacia hidrográfica.

A extração de propriedades morfométricas utilizando SIG, vem ganhando destaque e reconhecimento por ser uma escolha adequada quando comparada aos tratamentos tradicionais e à avaliação manual dos mapas topográficos, pois as bacias reduzem o tempo necessário para a geração de planos de informações para modelos hidrológico (COLOMBO et 


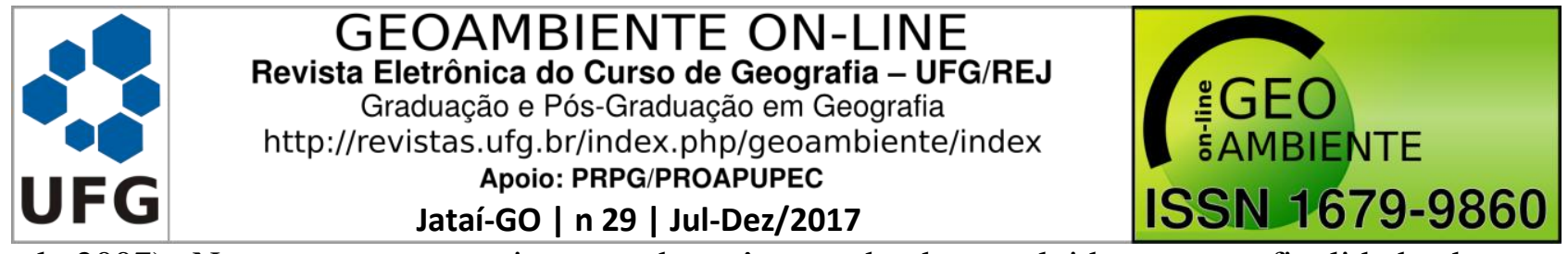

al. 2007). Nesse contexto, muitos estudos vêm sendo desenvolvidos com a finalidade de analisar, comparar, e ou atualizar informações de superfície terrestre por meio de dados SRTM (ALCARAZ et al., 2009; OLIVEIRA et al., 2010; ELESBON et al., 2011; FERREIRA et al., 2012).

Dessa forma, este estudo objetivou avaliar as propriedades morfométricas da bacia do Rio Ivaí, utilizando-se de técnicas de geoprocessamento de forma a fornecer dados para planejamento e gestão de bacias hidrográficas do Estado do Paraná.

\section{Material e métodos}

O estudo foi realizado na bacia hidrográfica do rio Ivaí (Figura 1), que se localiza na

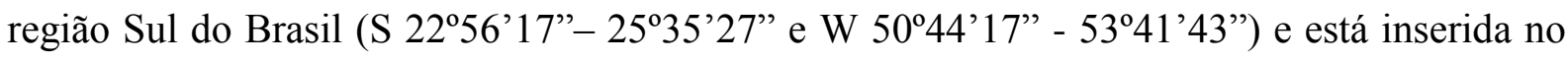
território paranaense. Sua área estende-se pelos Segundo e Terceiro Planaltos Paranaenses. Desde sua formação na confluência dos rios dos Patos e São João, na Serra da Boa Esperança (Segundo Planalto), numa altitude de $800 \mathrm{~m}$, o rio Ivaí percorre $671 \mathrm{~km}$ até desaguar no rio Paraná, município de Querência do Norte (PR), a uma altitude de $230 \mathrm{~m}$. O rio Ivaí apresenta vazão média, verificada entre os anos de 1974 a 2007 de $689 \mathrm{~m}^{3} \mathrm{~s}^{-1}$ e drena uma área de $36.587 \mathrm{~km}^{2}$ (LELI et al. 2010).

Figura I. Localização da bacia hidrográfica do rio Ivaí - Paraná

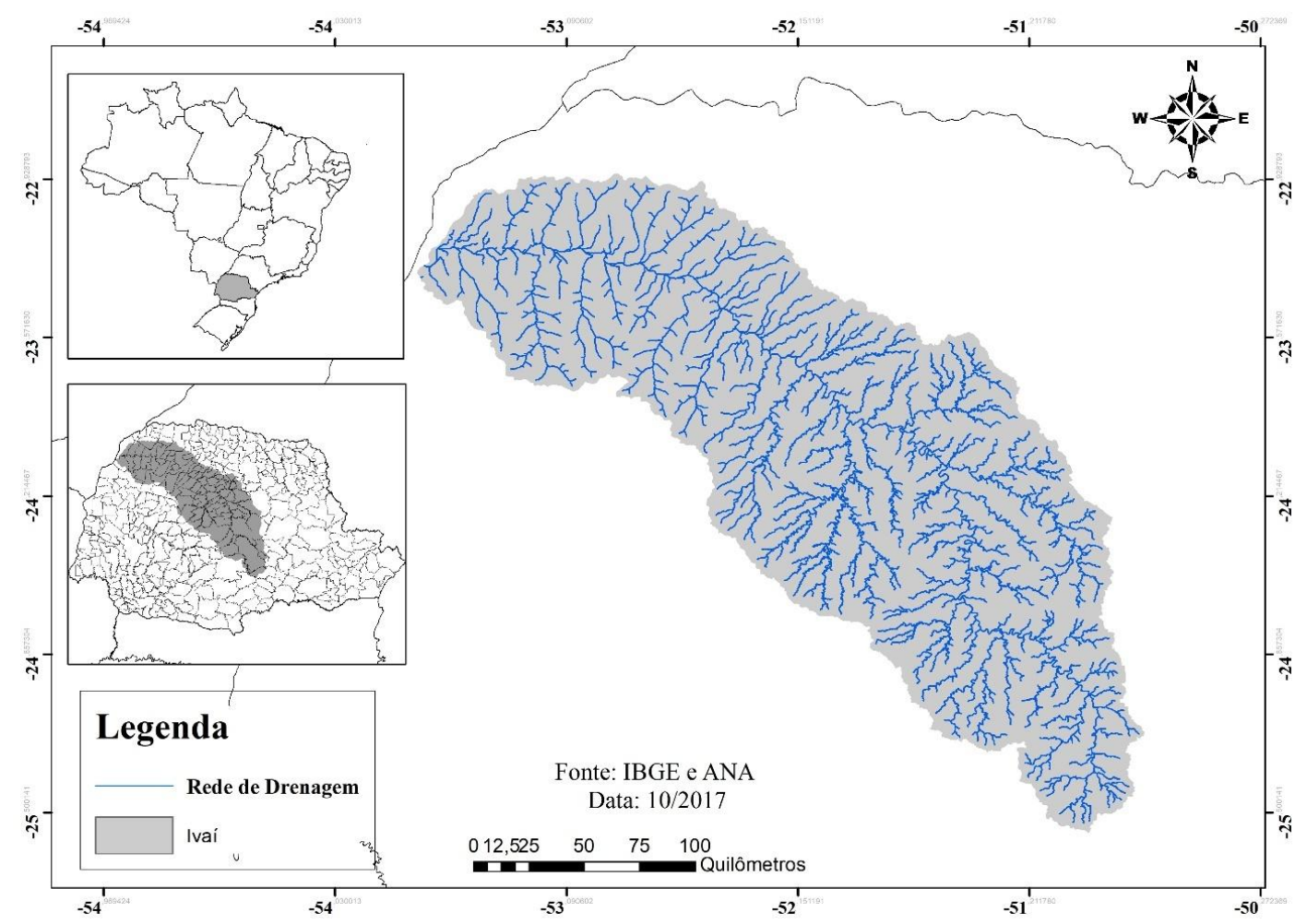

Organização: Próprio autores 


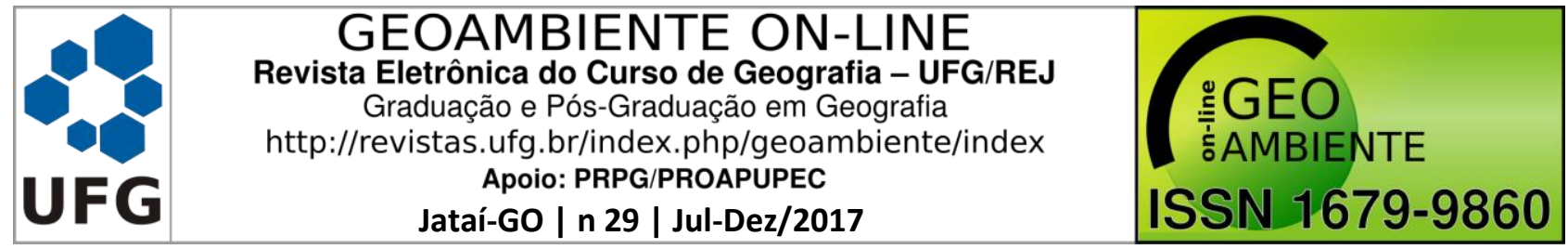

Os dados SRTM (Shuttle Radar TopographyMission) foram adquiridos do site da EMBRAPA (Empresa Brasileira de Pesquisa Agropecuária). As cartas que abrangem a região da Bacia do Rio Ivaí são: SG-22-V-B, SG-22-X-A, SG-22-V-D, SG-22-X-C, SF-22-Y-A, SF22-Y-D, SF-22-Y-C. Estas cartas foram utilizadas para montar o mosaico com todas as SRTM e em seguida foi feito o "clip" com o perímetro para que ficasse apenas a área da bacia na imagem. O pré-processamento dos dados foi realizado em ambiente SIG utilizando o aplicativo computacional ArcGIS 10.4/ArcMap® (ESRI, 2017).

As cartas originais possuem o sistema de referência GCS-WGS84 (GeographicCoordinate System - World Geodetic System 1984). Para o processamento dos dados, o sistema foi alterado para o de coordenadas planas SIRGAS 2000 UTM-22S, onde localiza-se a bacia (Sistema de Referência Geocêntrico para as Américas - Universal Transversa de Mercator - Zona 22S).

Os procedimentos para a delimitação da bacia do rio Ivaí foram realizados utilizando a extensão ("plugin") SpatialAnalyst., utilizando as ferramentas "fillsinks" para o preenchimento de depressões e correção de falhas do relevo, "flowdirection" para determinar a direção de fluxo, "flowaccumulation" para determinar o fluxo acumulado. Os coeficientes morfométricos obtidos estão descritos na Tabela I.

Tabela I. Descrição dos parâmetros morfométricos calculados para a bacia do rio Ivaí.

\begin{tabular}{|c|c|c|c|}
\hline Parâmetro & Equação & Objetivo & Tendência a enchentes \\
\hline $\begin{array}{c}\text { Coeficiente de } \\
\text { compacidade (Kc) }\end{array}$ & $\mathrm{K}_{\mathrm{c}}=0,28 * \frac{\mathrm{P}}{\sqrt{\mathrm{A}}}$ & $\begin{array}{l}\text { Relaciona a bacia a } \mathrm{um} \\
\text { círculo. }\end{array}$ & $\begin{array}{c}1,00-1,25=\text { alta } \\
1,25-1,50=\text { média } \\
<1,50=\text { baixa }\end{array}$ \\
\hline $\begin{array}{l}\text { Fator de forma } \\
\qquad(\mathbf{K f})\end{array}$ & $\mathrm{K}_{\mathrm{f}}=\frac{\mathrm{A}}{\mathrm{L}^{2}}$ & $\begin{array}{l}\text { Relação entre largura e } \\
\text { comprimento para avaliação } \\
\text { de geometria. }\end{array}$ & $\begin{array}{c}\geq 0,75=\text { alta } \\
0,75-0,50=\text { média } \\
\leq 0,50=\text { baixa }\end{array}$ \\
\hline $\begin{array}{c}\text { Índice de } \\
\text { Circularidade (IC) }\end{array}$ & $\mathrm{I}_{\mathrm{c}}=\frac{12.57 * \mathrm{~A}}{\mathrm{P}^{2}}$ & $\begin{array}{l}\text { Quanto mais próximo do } \\
\text { valor } 1 \text { maior a circularidade } \\
\text { e mais sujeita a inundações. }\end{array}$ & $\begin{array}{l}>0,51=\text { alta } \\
0,51=\text { média } \\
<0,51=\text { baixa }\end{array}$ \\
\hline $\begin{array}{c}\text { Índice de } \\
\text { Rugosidade (IR) }\end{array}$ & $\mathrm{I}_{\mathrm{r}}=\mathrm{Dd}^{*} \mathrm{H}$ & $\begin{array}{l}\text { Combina a diferença de nível } \\
\text { da bacia e a densidade de } \\
\text { drenagem, onde valores altos } \\
\text { indicam vertentes íngremes e } \\
\text { longas. }\end{array}$ & - \\
\hline
\end{tabular}




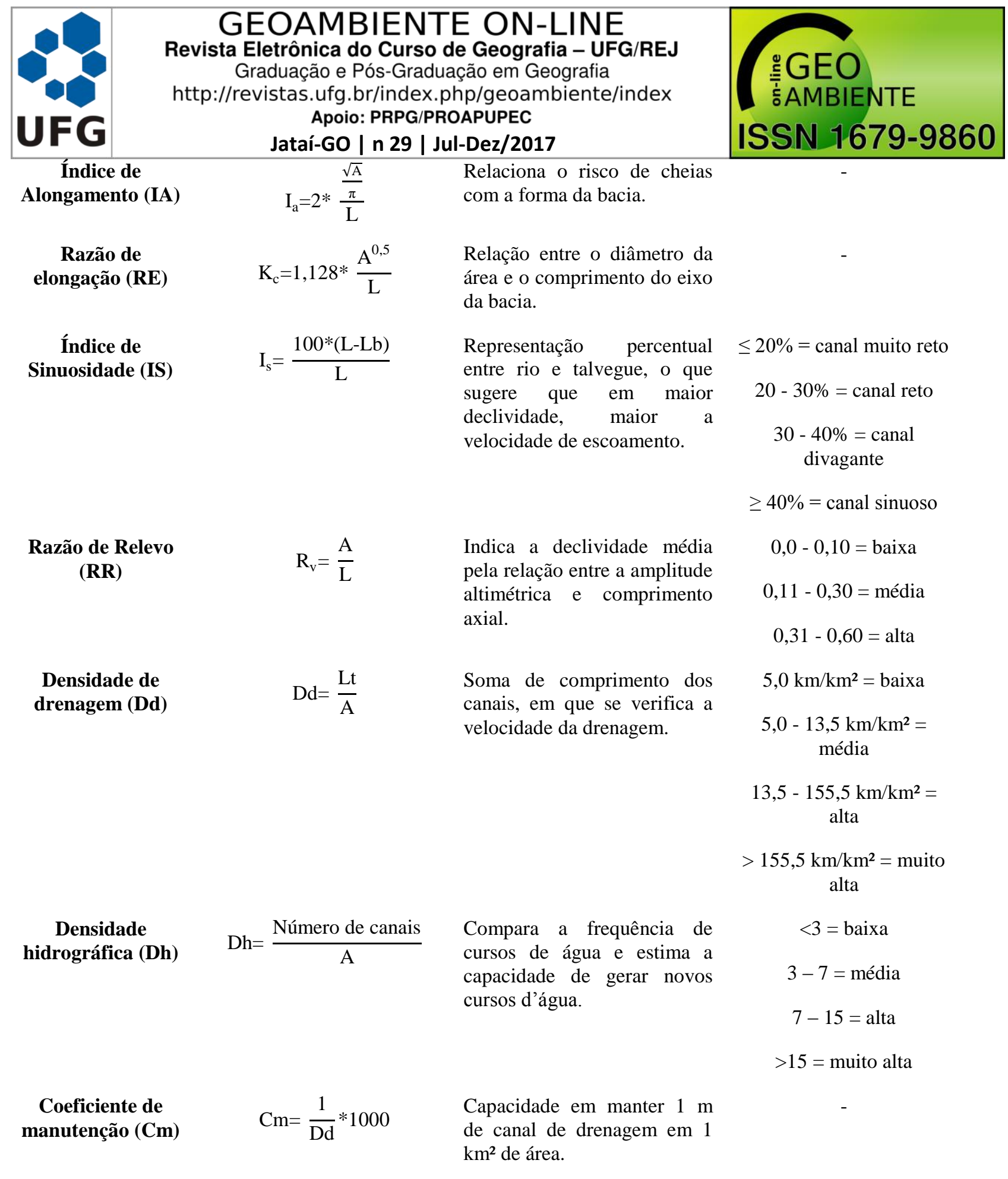

Fonte: Horton (1932), Miller (1953), Schumm (1956) e Horton, 1945).

Em que: P: perímetro da bacia $(\mathrm{km})$; A: área da bacia $\left(\mathrm{km}^{2}\right)$; L: comprimento do canal principal $(\mathrm{km})$; Dd: densidade de drenagem $\left(\mathrm{km} / \mathrm{km}^{2}\right) ; \mathrm{H}$ : amplitude altimétrica $(\mathrm{km})$; Lb: comprimento da bacia; $\mathrm{Lt}$ : comprimento total dos canais $(\mathrm{km})$.

A ordem dos cursos d'água foi determinada segundo os critérios de Horton (1945) e Strahler (1957) e a classificação da declividade foi feita segundo a classificação da Embrapa (2013) (Tabela II). 


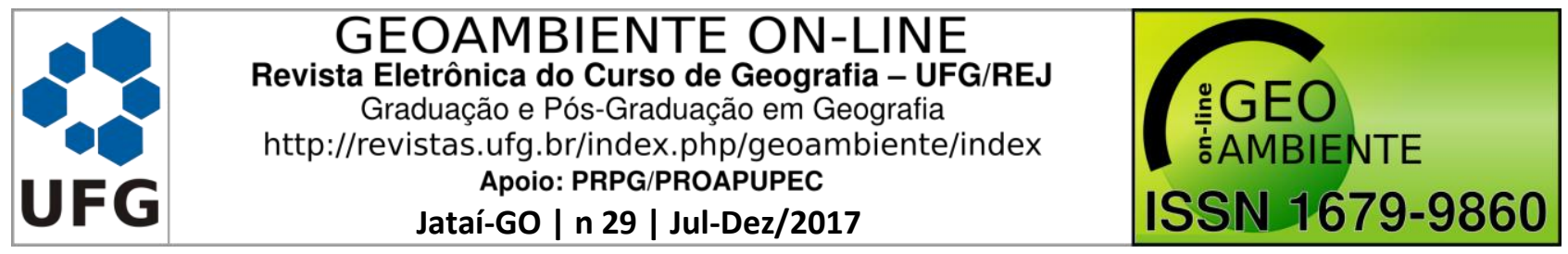

Tabela II. Classificação de declividade segundo Embrapa (2013).

\begin{tabular}{cc}
\hline Relevo & Classes de declive (\%) \\
\hline Plano & $0-3$ \\
Suavemente ondulado & $3-8$ \\
Ondulado & $8-20$ \\
Fortemente ondulado & $20-45$ \\
Montanhoso & $45-75$ \\
Escarpado & $>75 \%$ \\
\hline
\end{tabular}

\section{Resultados e discussão}

A Tabela III ilustra os parâmetros morfométricos encontrados para a bacia do rio Ivaí PR.

As principais medidas da bacia hidrográfica do rio Ivaí compreendem a área de drenagem de $36.525,49 \mathrm{~km}^{2}$, perímetro de $1.190,38 \mathrm{~km}$ e comprimento axial de $367,54 \mathrm{~km}$ (Tabela III). É possível perceber que os resultados para o fator de forma e o índice de circularidade foram muito baixos, o que pode ser entendido como um primeiro indicativo da forma da bacia, sendo nesse caso, mais alongado.

O coeficiente de compacidade revelou um valor alto e adimensional, variando de acordo com o formato da bacia (Villela e Mattos, 1975). Esse índice aumenta à medida que a forma da bacia deixa de ser circular. Tais resultados e a razão de elongação baixa, apontam que a bacia do rio Ivaí possui formato alongado e apresenta baixa probabilidade à ocorrência de enchentes em condições normais de precipitação. Bacias com formato irregular apresentam coeficiente de compacidade maior e bacias alongadas têm menos chance de chuvas intensas ocorrerem ao longo de sua área simultaneamente (CARDOSO et al., 2006).

A forma de uma bacia hidrográfica está diretamente relacionada com o tempo de concentração, ou seja, o tempo para a água infiltrar ou escoar após a precipitação. Em bacias alongadas, como a do rio Ivaí, os afluentes entram em contato com o principal curso d'água em diversos locais durante o fluxo. Em bacias circulares, a concentração do deflúvio ocorre em um só ponto, diminuindo o tempo de concentração e aumentando as chances de ocorrência de enchentes (SINGH et al., 2014). Além disso, bacias com formatos alongadas apresentam baixas possibilidades de chuvas intensas ocorrerem em toda sua extensão simultaneamente (LORENZON et al., 2015a). 


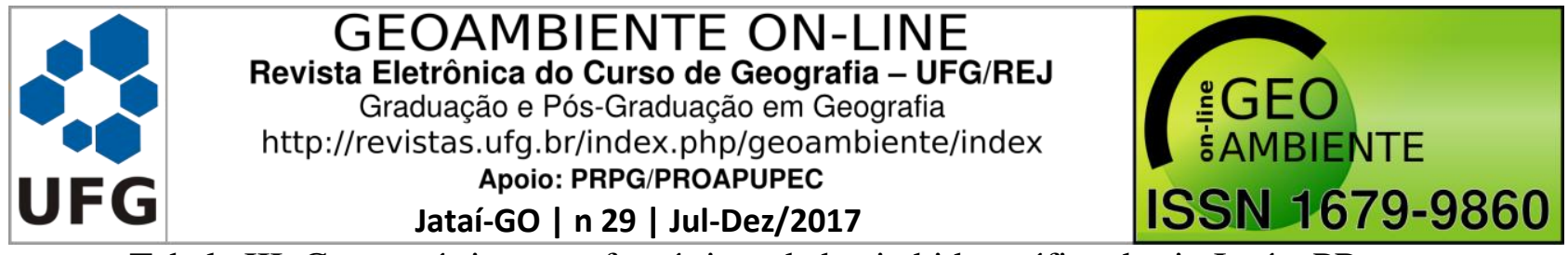

Tabela III. Características morfométricas da bacia hidrográfica do rio Ivaí - PR.

\begin{tabular}{|c|c|}
\hline Características geométricas & Resultados \\
\hline Área de drenagem $\left(\mathrm{km}^{2}\right)$ & 36525,49 \\
\hline Perímetro (km) & 1190,38 \\
\hline Comprimento axial da bacia (km) & 367,54 \\
\hline Coeficiente de compacidade (Kc) & 1,744 \\
\hline Fator de forma $(\mathrm{F})$ & 0,27 \\
\hline Índice de circularidade (Ic) & 0,32 \\
\hline Índice de rugosidade (Ir) & 113,03 \\
\hline Índice de alongamento (Ia) & 0,42 \\
\hline Razão de elongação (Re) & 0,59 \\
\hline \multicolumn{2}{|l|}{ Características do relevo } \\
\hline Declividade máxima (\%) & 130,65 \\
\hline Declividade média (\%) & 10,36 \\
\hline Declividade mínima (\%) & 0 \\
\hline Altitude máxima (m) & 1338 \\
\hline Altitude média (m) & 565,19 \\
\hline Altitude mínima (m) & 217 \\
\hline Índice de sinuosidade (Is) & 1,56 \\
\hline Razão de relevo (Rr) & 0,003 \\
\hline \multicolumn{2}{|l|}{ Características da Rede de Drenagem } \\
\hline Comprimento total de todos os canais $(\mathrm{km})$ & 8299,81 \\
\hline Comprimento do canal principal (km) & 502,52 \\
\hline Densidade hidrográfica $\left(\mathrm{km} / \mathrm{km}^{2}\right)$ & 0,02 \\
\hline Densidade de drenagem $\left(\mathrm{km} / \mathrm{km}^{2}\right)$ & 0,23 \\
\hline Coeficiente de manutenção (m²/m) & 4400,76 \\
\hline Ordem da bacia & 5 \\
\hline Forma da bacia & Alongada \\
\hline
\end{tabular}

Caracterizações semelhantes foram encontradas por Georgin, Oliveira e Rosa (2015) nas bacias hidrográficas do Alto Jacuí e Vacacaí, no Estado do Rio Grande do Sul, as quais 


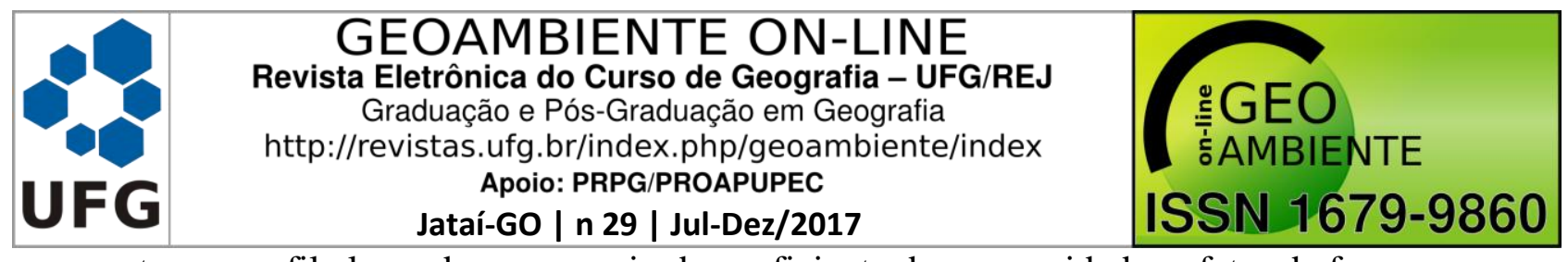

apresentaram perfil alongado e, por meio do coeficiente de compacidade, o fator de forma e $o$ índice de circularidade indicaram que são pouco susceptíveis a enchentes.

Em relação ao índice de rugosidade da bacia (IR), Sousa e Rodrigues (2012) relacionam valores de IR inferiores a $150 \mathrm{~m}$ como fracos e com declividade média em torno de $3 \%$. Para a bacia do rio Ivaí, o IR foi de 113,038 , indicando que esta bacia não apresenta susceptibilidade erosiva ocasionada por escoamentos superficiais erosivos.

O índice de sinuosidade varia de 1 a 2 , indicando que valores próximos a 1 sugerem canais retilíneos, ao passo que valores superiores a 2,0, indicam sinuosidadedos canais. Valores intermediários sugerem formas transicionais, regulares e irregulares. O resultado encontrado para a bacia do rio Ivaí sugere transição entre formas regulares e irregulares, com canais retilíneos e sinuosos.

A razão de relevo de $0,003 \mathrm{~km} / \mathrm{km}^{-1}$ assinala a baixa relação do relevo com o formato da bacia alongada e a baixa amplitude altimétrica para a bacia do rio Ivaí. Coutinho et al. (2011) e Santos e Morais (2012) também obtiveram valores baixos para esse índice, de 0,0970 $\mathrm{km} / \mathrm{km}^{-1}$ e $0,0015 \mathrm{~km} / \mathrm{km}^{-1}$, respectivamente.

Ainda pelos valores da Tabela 3, a densidade de drenagem de valor $0,23 \mathrm{~km} \mathrm{~km}^{-2}$ pode ser considerada baixa $(\leq 5,0)$, de acordo com a proposta de Sthraler (1957), assim como a densidade hidrográfica (Dh) de $0,23 \mathrm{~km} \mathrm{~km}^{-2}$. Segundo Silva e Melo (2006), esses dados sugerem que a relação entre a área da bacia e o comprimento dos rios é baixa.

Alves e Castro (2003) afirmam que a densidade hidrográfica compara a área da bacia com a quantidade total de números de canais fluviais, perenes, efêmeros e intermitentes mapeados. Dessa forma, esse parâmetro está relacionado com a eficácia hídrica e a capacidade de geração de novos canais. A densidade hidrográfica obtida revela que existe menos de 1 canal por $\mathrm{km}^{2}$. Santos e Morais (2012) encontraram um valor de 1,8608 canais $/ \mathrm{km}^{2}$ para a bacia do rio Lago Verde e sugerem que esse resultado inferior indica que características físicas e topográficas podem ser obstáculos para a formação de novos canais fluviais na bacia. Fato semelhante ocorre na bacia do rio Ivaí.

Antoneli e Thomaz (2007) afirmam que a densidade de drenagem é um parâmetro relevante na indicação do grau de desenvolvimento e eficiência do sistema de drenagem de uma bacia. Villela e Mattos (1975) também destacam a importância desse índice e afirmam que o mesmo pode variar de $0,5 \mathrm{~km} \mathrm{~km}^{-2} \mathrm{em}$ bacias com drenagem pobre, a $3,5 \mathrm{~km} \mathrm{~km}^{-2}$ ou mais, em bacias bem drenadas. 


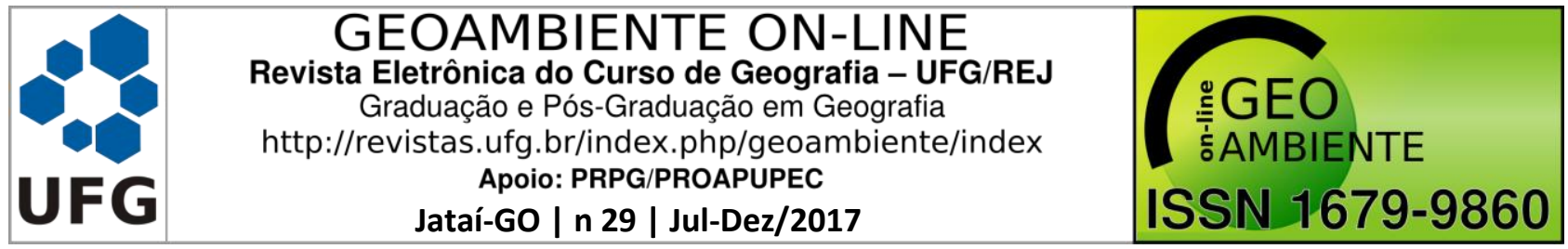

Outro parâmetro morfométrico significativo refere-se ao coeficiente de manutenção, que por sua vez, objetiva calcular a área mínima que a bacia necessita para a manutenção de um metro de canal fluvial, obtido em $\mathrm{m}^{2} / \mathrm{m}$ (SANTOS e MORAIS, 2012). O coeficiente de manutenção encontrado indica que, em média, os canais da bacia do rio Ivaí possuem $4400,476 \mathrm{~m}^{2} / \mathrm{m}$ para a área e evolução da drenagem. Morais e Almeida (2010) reconhecem que os resultados desse índice são inversos ao índice da densidade de drenagem.

A análise do sistema de drenagem da bacia hidrográfica do rio Ivaí (Tabela IV) aponta que essa bacia é classificada como de $5^{\mathrm{a}}$ ordem, conforme classificação de Strahler (1952) (Figura 2), sendo bem ramificada. A ramificação da rede de drenagem pode intervir no sistema de drenagem, pois, quanto maior a ramificação, melhor será a drenagem (TONELLO et al., 2006).

As informações quantitativas referentes à declividade da bacia (Tabela V e Figura III) apontam que a maior parte do relevo está compreendido na classe suavemente ondulado $(47,15 \%)$ e ondulado $(29,99 \%)$ de acordo com a classificação da Embrapa (2013) com declividade média de 10,36\%.

A declividade indica tendência de baixa velocidade no escoamento superficial, aumentando a possibilidade da infiltração de água no solo. RODRIGUES et al., 2016 avaliaram as características morfométricas e a declividade da bacia hidrográfica do igarapé da Prata e concluíram que o relevo dessa bacia se apresenta, em grande parte, como suavemente ondulado, semelhante ao encontrado para a bacia em estudo.

A declividade é um parâmetro que deve ser observado em bacias hidrográficas, pois, áreas que apresentam declividade acentuada, apresentam acelerada concentração da água da chuva, o que influencia significativamente na ocorrência de picos de enchentes. Cardoso et al. (2006) e Tonello et al. (2006) afirmam que a declividade de uma bacia hidrográfica acomete de maneira significativa a velocidade do escoamento superficial, reduzindo a infiltração de água no solo e intensifica o processo erosivo do solo (PISSARRA et al., 2010).

Calil et al. (2012) também destacam a influência da declividade, os quais reconhecem que o impedimento da infiltração em locais com alta declividade irá propiciar maior ramificação da rede hidrográfica, gerando densidade de drenagem mais alta e escoamento superficial mais eficiente. Pruski (2011) destaca que quanto mais acentuada a declividade de uma bacia, menor será sua capacidade de armazenamento superficial e maior a sua susceptibilidade à ocorrência de erosões. 


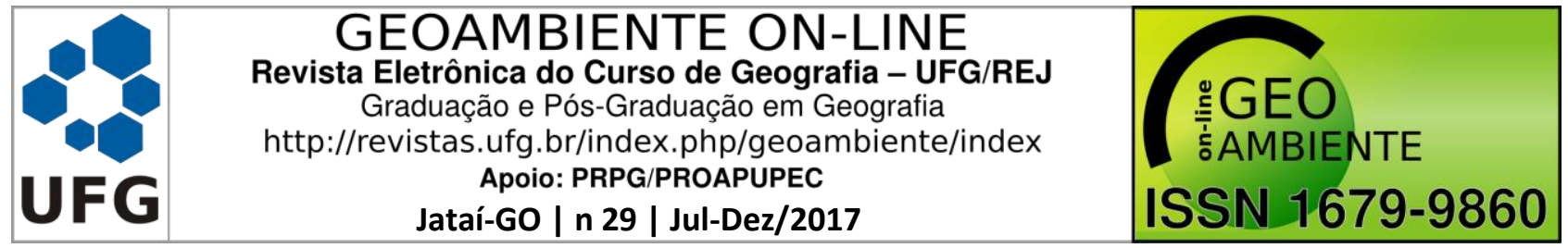

Tabela IV - Caracterização dos cursos d'água da bacia hidrográfica do Rio Ivaí - PR.

\begin{tabular}{ccc}
\hline Classe & Quantidade & Comprimento (km) \\
\hline 1 & 654 & 4061,09 \\
2 & 324 & 2299,53 \\
3 & 149 & 1058,18 \\
4 & 62 & 378,49 \\
5 & 116 & 502,52 \\
Total & 1305 & 8299,81 \\
\hline
\end{tabular}

Figura II. Ordenamento dos canais da bacia do Rio Ivaí - PR.

Classificação dos canais da Bacia do Rio Ivaí - PR.

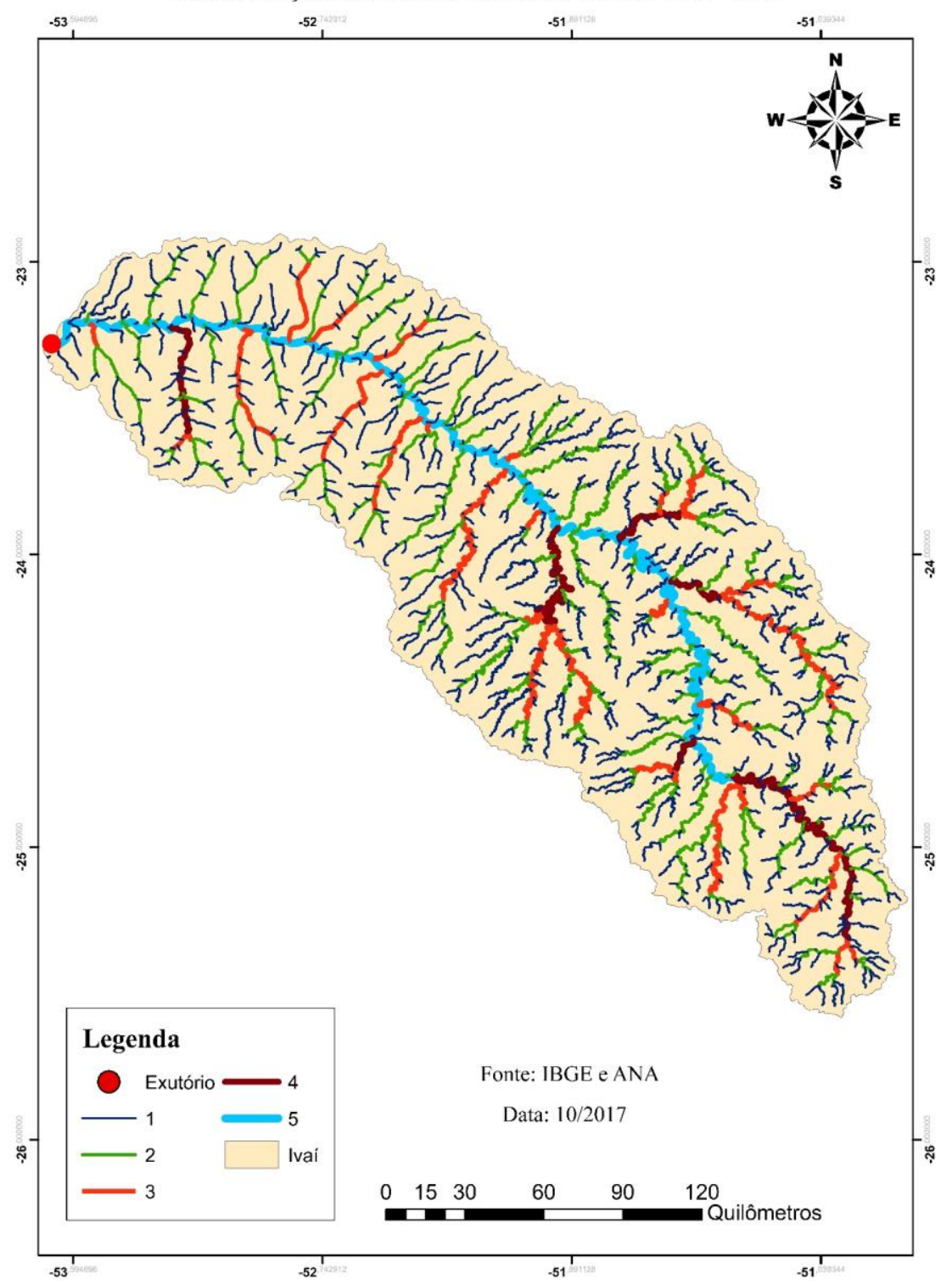




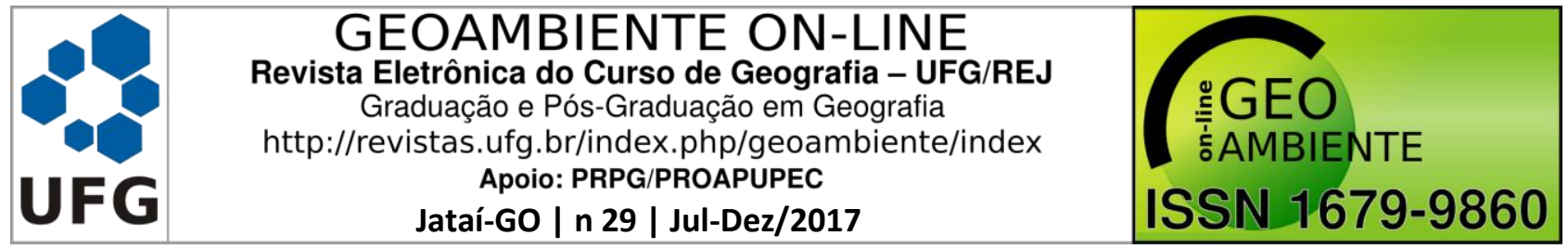

Tabela V. Distribuição das classes de declividade da bacia hidrográfica do rio Ivaí - PR.

\begin{tabular}{cccc}
\hline Relevo & Classes de declive (\%) & Área $\left(\mathbf{K m}^{2}\right)$ & Área $\mathbf{( \% )}$ \\
\hline Plano & $0-3$ & 6114,46 & 16,74 \\
Suavemente ondulado & $3-8$ & 17221,59 & 47,15 \\
Ondulado & $8-20$ & 10953,33 & 29,99 \\
Fortemente ondulado & $20-45$ & 2176,41 & 5,96 \\
Montanhoso & $45-75$ & 59,13 & 0,16 \\
Escarpado & $>75 \%$ & 0,57 & 0,002 \\
Total & & 36525,50 & 100
\end{tabular}

Figura III. Classificação da declividade da bacia do Rio Ivaí - PR.

Classificação das classes de declividade Bacia do Rio Ivaí - PR.

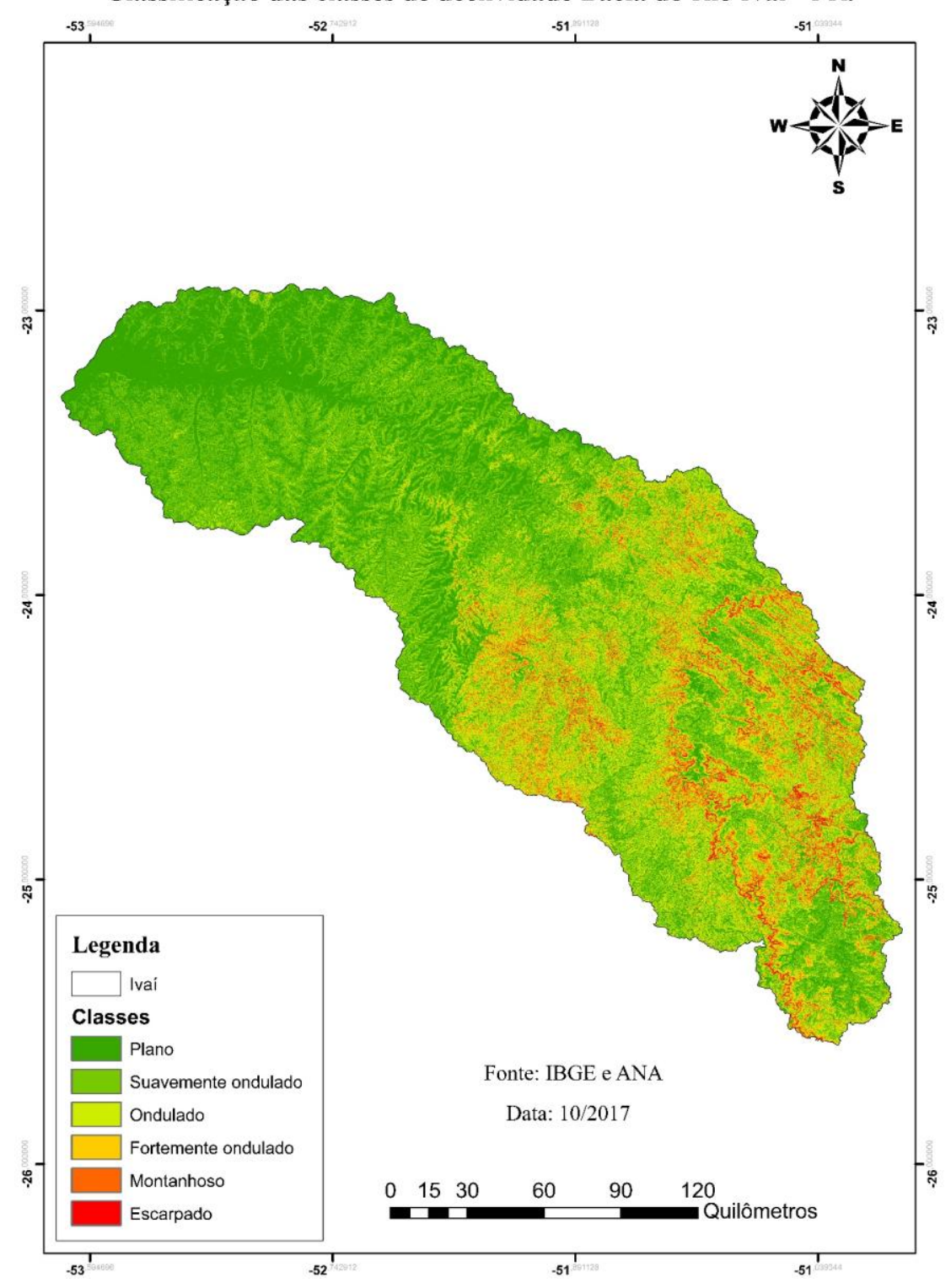




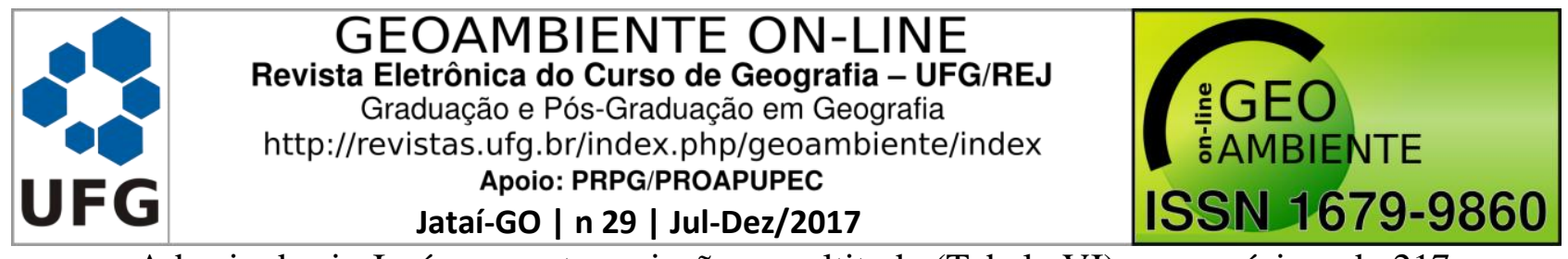

A bacia do rio Ivaí apresenta variações na altitude (Tabela VI), com mínima de 217 e máxima de 1338 m, apresentando altitude média de 565,19 m (Figura 4). Para Duarte et al. (2007), a variação da elevação e a elevação média de uma bacia hidrográfica tem grande correlação com a temperatura e a precipitação. Tais diferenças altimétricas em uma bacia podem ocasionar diferenças relevantes na temperatura média. Isso provoca variações na evapotranspiração e precipitação anual (SANTOS et al., 2012b).

Lorenzon et al. (2015b) analisaram a influência das características morfométricas da bacia hidrográfica do rio Benevente nas enchentes no município de Alfredo Chaves-ES e concluíram que a alta variação de altitude desta bacia juntamente com os fatores climáticos ocasiona a formação de chuvas orográficas, as quais apresentam alto potencial para causar enchentes devido à sua curta duração e alta intensidade.

Alves et al. (2017) obtiveram altitude máxima de 920 m, altitude média de 808,89 m, altitude mínima de $635 \mathrm{~m}$ e amplitude altimétrica de $285 \mathrm{~m}$ para a bacia hidrográfica do córrego Bonsucesso. Esses valores diferem dos encontrados para a bacia em estudo, que apresentou amplitude altimétrica de $1121 \mathrm{~m}$, não sendo indicada para agricultura, de acordo com a orientação de Zanata et al. (2011).

Tabela VI. Distribuição das classes de altitudes da bacia hidrográfica do rio Ivaí - PR.

\begin{tabular}{ccc}
\hline Altitude $(\mathbf{m})$ & Área $\left(\mathbf{K m}^{\mathbf{2}}\right)$ & Área (\%) \\
\hline $1-217$ & 4762,23 & 13,04 \\
$217-423$ & 7200,88 & 19,72 \\
$423-510$ & 6036,55 & 16,53 \\
$510-605$ & 5142,02 & 14,08 \\
$605-709$ & 3978,72 & 10,89 \\
$709-810$ & 4016,00 & 11,00 \\
$810-914$ & 2617,28 & 7,17 \\
$914-1.053$ & 1763,70 & 4,83 \\
$1.053-1.338$ & 1008,11 & 2,76 \\
\hline Total & 36525,49 & 100,00 \\
\hline
\end{tabular}




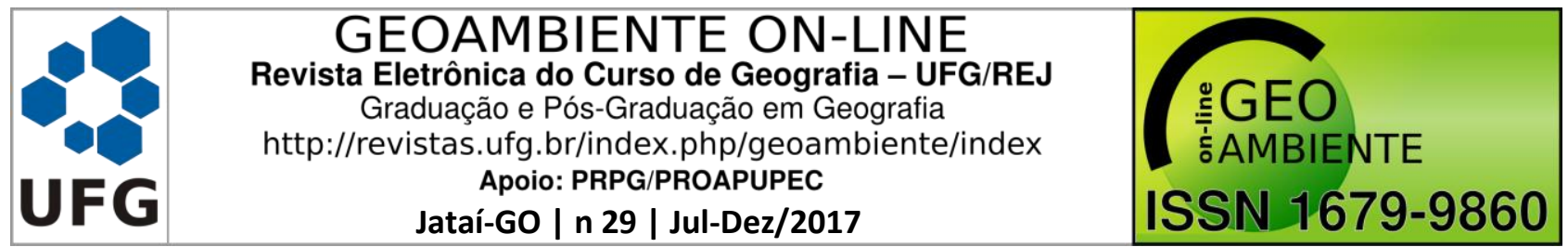

Figura IV. Distribuição espacial da elevação na bacia hidrográfica do Rio Ivaí - PR.

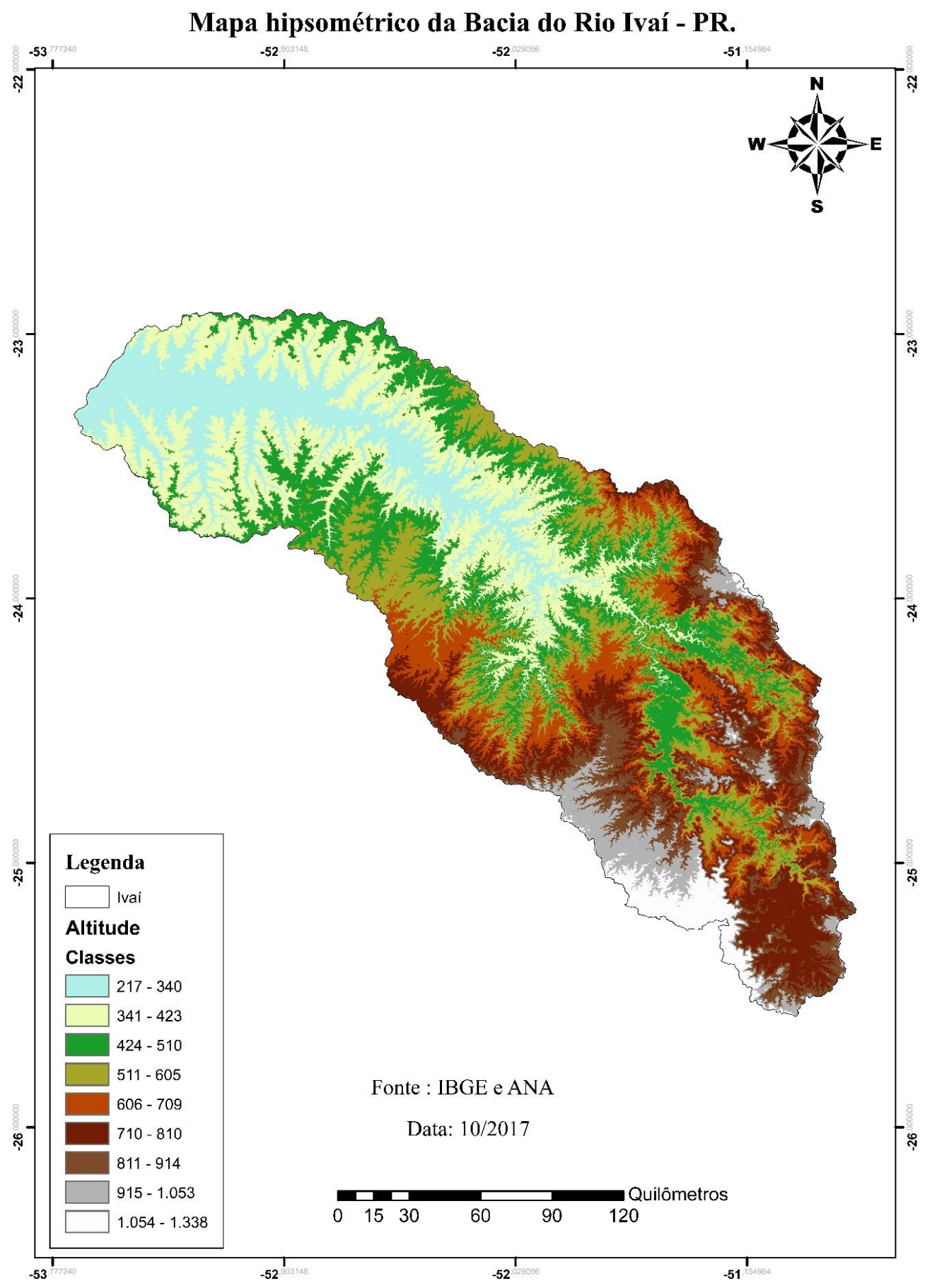

\section{Conclusão}

- A análise dos dados morfométricos permitiu compreender o regime hidrológico e inferir sobre o manejo e conservação da bacia do rio Ivaí. A bacia apresenta formato alongado, com baixa susceptibilidade a enchentes em condições normais de precipitação. Os índices encontrados indicam que a bacia não apresenta 


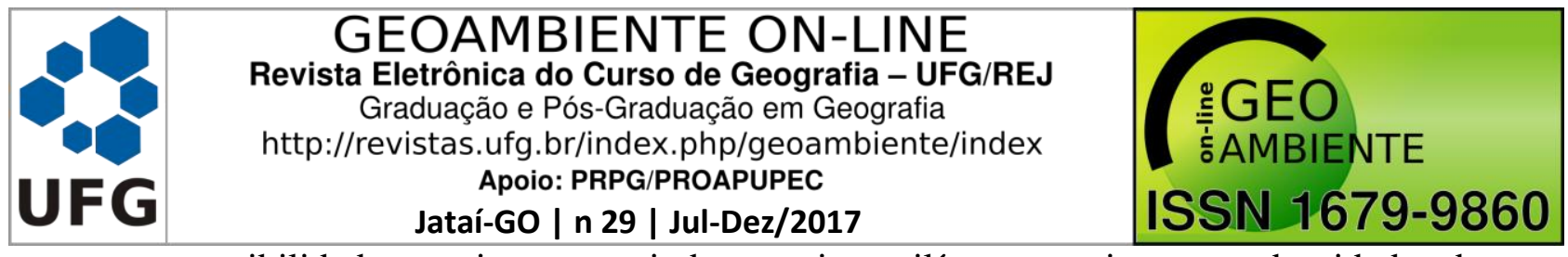

susceptibilidade erosiva, possuindo canais retilíneos e sinuosos, densidade de drenagem baixa e bem ramificada. Além disso, a bacia apresenta a maior parte do seu relevo nas classes suavemente ondulado e ondulado $(77,14 \%)$ com altitude mínima de $217 \mathrm{~m}$ e máxima de $1.338 \mathrm{~m}$ que podem provocar alterações na temperatura média.

- A partir de tais informações, este estudo pode contribuir para um melhor planejamento ambiental e tomada de decisões quanto à gestão dos recursos hídricos da bacia do rio Ivaí.

\section{Referências}

ALCARAZ, S. A.; SANNIER, C.; VITORINO, A. C. T.; DANIEL, O. Comparison of methodologies for automatic generation of limits and drainage networks for hidrographic basins. Revista Brasileira de Engenharia Agrícola e Ambiental, Campina Grande, v.13, n.14, p.369-375, jul/ago. 2009.

ALVES, W.S.; MORAIS, W.A.; SALEH, B.B.; SANTOS, L.N.S. Análise de aspectos físicos da bacia do córrego de Bonsucesso, localizada em Jataí (GO), Brasil, apoiado em geotecnologias.Revista Geográfica Acadêmica, Boa Vista, v. 11, n. 1 p. 13-34. 2017.

ALVES, W. S.; SCOPEL, I. MARTINS, A. P.; MORAIS, W. A. Analise morfométrica da bacia do Ribeirão das Aboboras - Rio Verde (GO).Geociências, Rio Claro, v.35, n. 4, p.652$667,2016$.

ALVES, J.; CASTRO P. de T. A. Influência de Feições Geológicas na Morfologia da Bacia do Rio Tanque (MG) Baseada no Estudo de Parâmetros Morfométricos e Análise de Padrões de Lineamento. Revista Brasileira de Geociências, São Paulo, v.33, n.2. p.117-124. 2003.

ANTONELI, V; THOMAZ, E.L. Caracterização do meio físico da bacia do Arroio Boa Vista, Guamiranga-PR.Revista Caminhos da Geografia, Uberlândia, v.8, n.21, p. 46-58, jun. 2007. CALIL, P. M.; OliveirA, L. F. C. de; KLIEMANN, H. J.; OliVEIRA, V. A. de. Caracterização geomorfométrica e do uso do solo da bacia hidrográfica do Alto Meia Ponte, Goiás. Revista Brasileira de Engenharia Agrícola e Ambiental, Campina Grande, v. 16, n. 4, p. 433-442, 2012.

CARDOSO, A. C.; DIAS, H.C.T.; SOARES, C.P.B.; MARTINS, S.V. Caracterização morfométrica da bacia hidrográfica do rio Debossan, Nova Friburgo, RJ. Revista Árvore. Curitiba,v.30, p. 241 - 248mar./abril2006. 


\begin{tabular}{|c|c|c|}
\hline & $\begin{array}{c}\text { GEOAMBIENTE ON-LINE } \\
\text { Revista Eletrônica do Curso de Geografia - UFG/REJ } \\
\text { Graduação e Pós-Graduação em Geografia } \\
\text { http://revistas.ufg.br/index.php/geoambiente/index } \\
\text { Apoio: PRPG/PROAPUPEC }\end{array}$ & $\begin{array}{l}: G E O \\
: \text { GMBIENTE }\end{array}$ \\
\hline & Jataí-GO | n 29 | Jul-Dez/2017 & ISSN 1679-9860 \\
\hline
\end{tabular}

COUTINHO, L.M.; CECÍLIO, R.A.; XAVIER, A.C.; ZANETTI, S.S.; GARCIA, G.D.O.

Caracterização morfométrica da bacia hidrográfica do rio da prata, Castelo, ES. Irriga, Botucatu, v. 16, n. 4, p. 369-381, out/dez. 2011.

COLOMBO, R.; VOGT, J.; SOILLE, P.; PARACCHINI, M. L.; JAGER, A. de.Deriving river networks and catchments at the European. Catena, Amsterdam, v.70, n.3, p.296-305, jul./set. 2007.

DUARTE, C.C.; GALVÍNCIO, J.D.; CORRÊA, A.C.B.; ARAÚJO, M.S.B. Análise fisiográfica da bacia hidrográfica do rio Tapacurá-PE. Revista de Geografia, Recife, v.24, n.2, p.50-64,set./dez. 2007.

ELESBON, A. A. A.; GUEDES, H.A.S.; SILVA, D.D.D.; OLIVEIRA, I.D.C. Uso de dados SRTM e plataforma SIG na caracterização morfométrica da bacia hidrográfica do Braço Norte do Rio São Mateus - Brasil. Revista Escola de Minas, Ouro Preto, v. 64, n.3, p.281288, jul./set. 2011.

EMBRAPA, Empresa Brasileira de Pesquisa Agropecuária. Sistema Brasileiro de Classificação de Solos.3 ed. Brasilia, Embrapa solos, 2013, 353 p.

ESRI - Environmental Systems Research Institute. Inc. ArcGIS Professional GIS for the desktop, v.10.4 Disponívelem: http://www.img.com.br/pt-BR/arcgis10-4/sobre-arcgis. Acesso em: 24 set. 2017.

FERREIRA, R. G.; MOURA, M. C. O.; CASTRO, F. S. Caracterização morfométrica da subbacia do Ribeirão Panquinhas, ES. Enciclopédia Biosfera, Rio Verde, v.8, n.15, p.22472256, out. 2012.

FRAGA, M. S.; FERREIRA, R. G.; SILVA, F. B.; VIEIRA, N. P. A.; SILVA, D. P.; BARROS, F. M.; MARTINS, I. S. B. Caracterização morfométrica da bacia hidrográfica do Rio Catolé Grande, Bahia, Brasil. Nativa, Sinop, v. 2, n. 4, p. 214-218,out./dez. 2014.

GEORGIN, J.; OLIVEIRA, G. A.; ROSA, A. L. D. da. Estudo comparativo de índices morfométricos relacionado com cheias nas bacias hidrográficas do Alto Jacuí e Vacacaí Vacacaí Mirim (RS). Revista Eletrônica em Gestão, Educação e Tecnologia Ambiental, Santa Maria, v. 19, n. 2, p. 1357-1364, maio 2015.

HORTON, R. E. Drainage basin characteristics. American Geophysical Union, Washington, v.13, n.1, p.350-361, 1932.

HORTON, R.E. Erosional development of streams and their drainage basins: ahydrophysical approach to quantitative morphology.Geological Society of America Bulletin. Virgínia, v.56, n.3, p.275-370, 1945. 


\section{GEOAMBIENTE ON-LINE \\ Revista Eletrônica do Curso de Geografia - UFG/REJ \\ Graduação e Pós-Graduação em Geografia \\ http://revistas.ufg.br/index.php/geoambiente/index \\ Apoio: PRPG/PROAPUPEC \\ Jataí-GO | n 29 | Jul-Dez/2017}

$\stackrel{\circ}{\Xi} \mathrm{EEO}$

亏̇AMBIENTE

ISSN $1679-9860$

LELI, I.T.; STEVAUX, J.C.; NÓBREGA, M.T. Dinâmica espacial da hidrologia da bacia do Rio Ivaí. Boletim de Geografia, Maringá, v. 28, n. 2, p. 41-47, 2010.

LORENZON, A. S.; DIAS, H. C.; TONELLO, K. C. Escoamento superficial da água da chuva em um fragmento florestal de Mata Atlântica, Viçosa-MG. Revista Brasileira de Agropecuária Sustentável, Viçosa, v.5, n.1, p.50-58, jul. 2015a.

LORENZON, A.S.; FRAGA, M.S.; MOREIRA, A.R.; ULIANA, E.M.; SILVA, D.D.D.; RIBEIRO, C.A.A.S.; BORGES, A.C. Influência das características morfométricas da bacia hidrográfica do rio Benevente nas enchentes no município de Alfredo Chaves-ES. Revista Ambiente \& Água, Taubaté, v. 10, n. 1, p. 196-206, jan./mar. 2015 b.

OLIVEIRA, P. T. S. et al. Caracterização morfométrica de bacias hidrográficas através de dados SRTM. Revista Brasileira de Engenharia Agrícola e Ambiental, Campina Grande, v.14, n.8, p.819-825, ago. 2010.

MORAIS, F.; ALMEIDA, L. M. de. Geomorfologia Fluvial da Bacia Hidrográfica do Ribeirão Jaú, Palmas, estado do Tocantins. Brazilian Geographical Journal: Geosciences and Humanities Research Medium, Uberlandia, v. 1, n. 2, p. 331-351, jul. /dez. 2010.

MUKHERJEEA, S.; JOSHI, P. K.; MUKHERJEEA, S.; GHOSH, A.; GARG, R. D.; MUKHOPADHYAY, A. Evaluation of vertical accuracy of open source Digital Elevation Model (DEM). International Journal of Applied Earth Observation and Geoinformation, v. 21, p. $205-217$.

PISSARRA, T. C. T.; RODRIGUES, F. M.; POLITANO, W.; GALBIATTI, J. A. Morfometria de microbacias do Córrego Rico, afluente do Rio Mogi-Guaçu, Estado de São Paulo, Brasil. Revista Árvore, Viçosa, v. 34, n. 4, p. 669-676,jul./ago. 2010.

PRUSKI, F. F. Conservação de solo e água: práticas mecânicas para o controle da erosão hídrica. 2.ed. Viçosa: UFV, 2011. 240p.

RODRIGUES, R.S.S.; FERNANDES, L.L.; CRISPIM, D.L.; VIEIRA, A.S.A.; PESSOA, F.C.V. Caracterização morfométrica da bacia hidrográfica do Igarapé da Prata, Capitão Poço, Pará, Brasil. Revista Verde de Agroecologia e Desenvolvimento Sustentável, Pombal, v.11, n.3, p. 143-150,jul./set. 2016.

SANTOS, D. A. R.; MORAIS, F. D. Análise morfométrica da bacia hidrográfica do rio Lago Verde como subsídio à compartimentação do relevo da região de Lagoa da Confusão TO.Revista Geonorte, Manaus, Edição Especial, v.3, n.4, p. 617-629, 2012. 


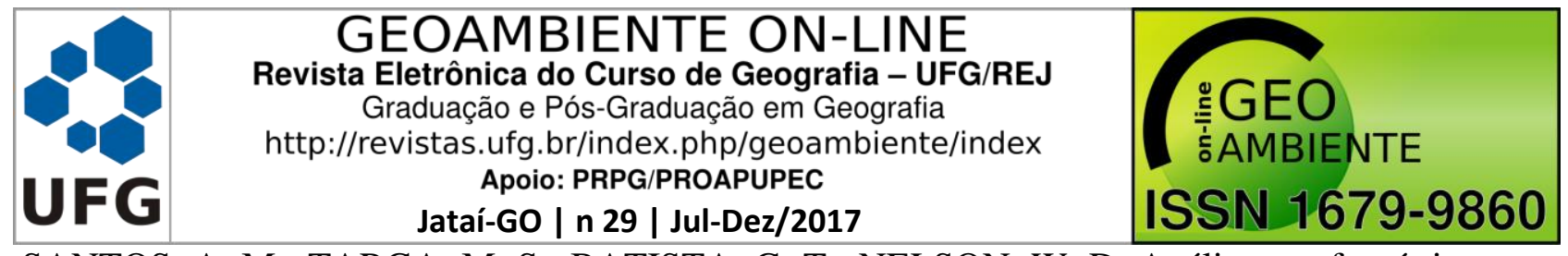

SANTOS, A. M.; TARGA, M. S.; BATISTA, G. T.; NELSON, W. D. Análise morfométrica das sub-bacias hidrográficas Perdizes e Fojo no município de Campos do Jordão, SP, Brasil. Revista Ambiente \& Água, Taubaté, v.7, n.3, 2012 b.

SIGH, P.; GUPTA, A.; SINGH, M. Hydrological inferences from watershed analysis for water resource management using remote sensing and GIS techniques. The Egyptian Journal of Remote Sensing and Space Science, Cairo, v. 17, n. 2, p. 111-121,dez. 2014.

SILVA, A. M.; MELLO, C.R, de; Apostila de Hidrologia. UFLA-MG, 2006.

SOUSA, F. A. de; RODRIGUES, S. C. Aspectos morfométricos da alta bacia do rio dos Bois em Iporá-GO.Mercator, Fortaleza, v. 11, n. 25, p. 141-151, mai./ago. 2012.

STRAHLER, A.N. Quantitative analysis of watershed geomorphology. Transactions: American Geophysical Union, Washington,v.38. p. 913 - 920. 1957.

TONEllo, K. C.; DIAS, H. C. T.; SOUZA, A. L. RIBEIRO, C. A. A. S.; LEITE, F. P. Morfometria da bacia hidrográfica da Cachoeira das Pombas, Guanhães- MG.Revista Árvore, Viçosa, v.30, n.5, p.849-857, set./out. 2006.

TRINDADE, S. P.; RODRIGUES, R. A. Uso do solo na microbacia do ribeirão samambaia e sua relação com a suscetibilidade a erosão laminar. Revista Geografia Acadêmica, Curitiba, v.10, n.1, p. 163-181, 2016.

VILLELA, S. M.; MATTOS, A. Hidrologia aplicada. São Paulo: McGraw-Hill do Brasil, 1975. 245p.

XAUD, M. R.; EPIPHANIO, J.C. N. Análise da dinâmica das conversões de uso e cobertura da terra na região sudeste de Roraima - Amazônia. RevistaAgro@mbiente On-line, Curitiba, v. 9, n. 4, p. 465- 475, out./dez. 2015.

ZANATA, M.; PISSARA, T. C. T.; ARRAES, C. L.; RODRIGUES, F. M.; CAMPOS, S. Influência da escala na análise morfométrica de microbacias hidrográficas. Revista Brasileira de Engenharia Agrícola e Ambiental, Campina Grande, v. 15, n. 10, p. 1062-1067, 2011. 